\begin{tabular}{|l|l|}
\hline \multicolumn{2}{|c|}{ Access this article online } \\
\hline Quick Response Code: & $\begin{array}{l}\text { Website: } \\
\text { www.annalsafrmed.org }\end{array}$ \\
\hline & DOI: \\
\hline & P.4103/1596-3519.129889 \\
\hline
\end{tabular}

\title{
A rare presentation of cervical fibroid in pregnancy
}

\author{
Page $\mid 88$ \\ Animesh C. Gandhi, Hemant I. Dugad, Yatin Shah \\ Department of Obstetrics and Gynaecology, Dr R. N. Cooper Municipal General Hospital and Oshiwara Municipal \\ Maternity Home, Mumbai, India
}

Correspondence to: Dr. Animesh Gandhi, A-3, 336, Jeevdani Darshan, Arunodaya Nagar, Mulund (East), Mumbai - 400 081, India. E-mail: animeshgandhi84@gmail.com

\begin{abstract}
Pregnancy in a fibroid uterus is not rare. However cervical fibroid is rare in pregnancy and has unique management challenges. We report a case of cervical fibroid in a Gravida2 Para1 patient that was found incidentally in a routine ultrasound in the second trimester. The fibroid grew in pregnancy till term, caused obstructed labour, a Cesarean section was required for the baby. Post surgery the fibroid prolapsed out of the introitus. Conservative management was decided to prevent surgical complications, delayed consequences of surgery and to preserve future child bearing. The case shows that conservative management over surgery is sometimes the appropriate choice.
\end{abstract}

Keywords: Cervical fibroid, conservative management, pregnancy

\section{Résumé}

Pevenir dans un fibrome utérus n'est pas rare. Cependant, fibrome du col utérin est rare pendant la grossesse et a des problèmes de gestion unique. Nous rapportons un cas de fibrome du col utérin chez une patiente de2 Para1 Gravida qui se trouvait par ailleurs à une échographie de routine au cours du deuxième trimestre. Le fibrome a augmenté pendant la grossesse jusqu'à terme, causée obstruée du travail, une césarienne est nécessaire pour le bébé. Après une chirurgie que du fibrome prolapsus de l'orifice vaginal. Gestion conservatrice a été décidée pour prévenir les complications chirurgicales, des conséquences retardées de chirurgie et de préserver l'enfant à naître portant. Le cas montre que la gestion conservatrice au cours de la chirurgie est parfois le choix approprié.

Mots-clés: Cervicale gestion conservateur, fibrome, grossesse

\section{Introduction}

Fibroids are the most common tumors of the uterus and the female pelvis. They represent an infrequent cause of infertility ${ }^{[1]}$ and pregnancy in a fibroid uterus is not rare. In today's obstetric practice, pregnancy in fibroid uterus has a prevalence of $10.7 \%^{[2]}$. A cervical fibroid with pregnancy is a rare occurrence, with unique management difficulties. About one third of fibroids increases in size during pregnancy ${ }^{[3,4]}$ and are associated with various complications. Antenatal complications like a miscarriage, bleeding in early pregnancy, degenerations in fibroid and preterm labour or preterm pre-labor rupture of membranes, placental abruption, fetal growth restriction and anomalies can occur. During labor and delivery there can be malpresentations, labor dystocia, caesarean delivery, postpartum haemorrhage, retained placenta or post myomectomy uterine rupture. ${ }^{[5]}$ An attempted myomectomy either abdominally or vaginally can be complicated by need for a hysterectomy in case of profuse uncontrollable haemorrhage ${ }^{[6]}$. However, few studies have shown relative safety of myomectomy in pregnancy in carefully selected patients. ${ }^{[7,8]}$

We report a unique case of cervical fibroid with pregnancy, which had an uneventful antenatal course but post caesarean section the fibroid prolapsed out 
of the introitus. Another unique point is that it was managed conservatively giving due consideration to the patient's wishes and the situation.

\section{Case History}

A 30 year old Gravida Para $_{1}$ Living $_{1}$, with previous full term normal delivery two years ago registered antenatally at 28 weeks of gestation. Routine ultrasound done for the patient incidentally revealed a hypoechogenic mass in the posterior cervix measuring six by six $\mathrm{cm}$ in size suggestive of a posterior cervical fibroid. The patient was asymptomatic. Her haemoglobin at registration was $8.5 \mathrm{~g} \%$.

A thorough counselling of the patient was done as regards her condition and the possible outcomes and complications that could ensue during her gestation and her delivery.

The patient stayed asymptomatic till term. Serial ultrasound demonstrated that the fibroid grew in size till it was eight by eight $\mathrm{cm}$ at 36 weeks of gestation. Patient's haemoglobin had risen to $11 \mathrm{~g} \%$ as a result of iron supplements.

Mode of delivery was planned as an elective caesarean section at 38 weeks but patient presented with spontaneous onset of labour at 37 weeks 6 days of gestation. On clinical examination the cervix was $5 \mathrm{~cm}$ dilated with no engagement of fetal head even with good uterine contractions. A diagnosis of obstructed labour was made and emergency Cesarean section was carried out. The lower segment of uterus was reached easily and a healthy male baby of $2.760 \mathrm{~kg}$ was delivered without any difficulty. The fibroid was palpated and noted to be in the posterior cervical lip and was left undisturbed. There were no surgical complications.

Post surgery on day four in the wards patient complained of a mass coming out per vaginum.

On examination, it was the posterior cervical fibroid that had completely prolapsed out of the introitus as seen in [Figure 1]. The fibroid was seen to be occupying the entire posterior cervix and there was no stalk or a broader pedicle connecting fibroid to the posterior cervical lip.

Counselling of the patient and her family was done regarding the situation and the management options. Immediate or delayed post puerperal removal of the fibroid was discussed as well as medications to reduce fibroid size preoperatively were considered. Medications like GnRH analogues or depot progesterone injections could not be used as patient was four days postpartum and lactating. Interventional radiology was not considered due to financial constraints. The patient and her family desired another child. Conservative line of management was chosen by the patient at that moment with a planned delayed surgery post puerperium (6 weeks post partum).

The prolapsed fibroid was held in the vagina with the help of a simple rubber ring pessary [Figure 2] for a period of six weeks. An ultrasound done at six weeks post partum revealed that the fibroid had shrunk to a size of three by three $\mathrm{cm}$. The fibroid was seen to be occupying the entire posterior cervix and there was no stalk. There was no prolapse even without the ring pessary. The patient remained asymptomatic.

Giving due consideration to the patient's wishes and considering the possible surgical complications and delayed consequences of surgery, it was decided to

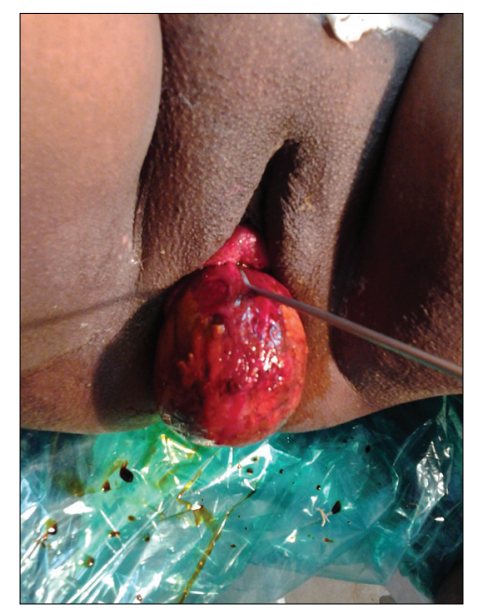

Figure 1: Prolapsed cervical fibroid on Post-operative day 4. The uterine sound shows the position of the external os of the cervix and the fibroid can be seen as a growth encompassing the entire posterior cervix

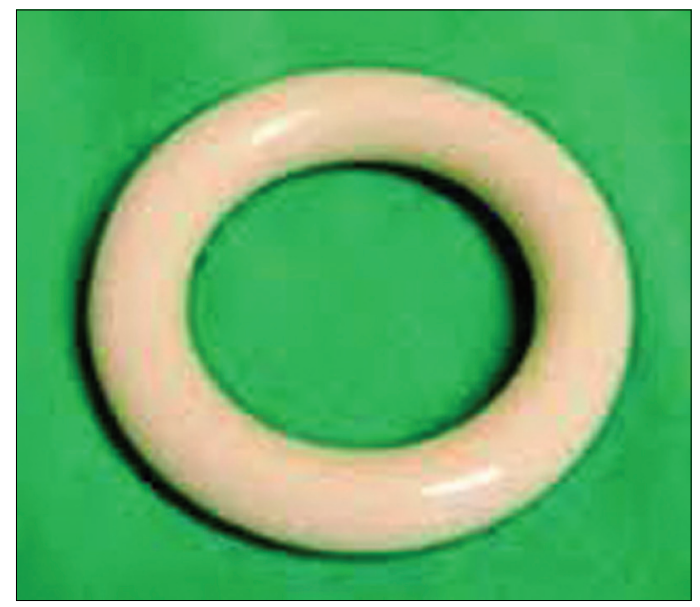

Figure 2: Simple rubber ring pessary 
continue the conservative line of management with monitoring of the size of the fibroid.

\section{Discussion}

In our case, the entire course of pregnancy was uneventful with no complications antenatally. The patient's condition was optimised in anticipation of surgical complications that might arise during the planned caesarean delivery. The caesarean section also was uneventful. A unique complication of post Caesarean section prolapsed cervical fibroid was seen in our case.

Post puerperal myomectomy was planned for this patient. However the patient was asymptomatic at six weeks post partum and the fibroid had reduced in size. A review of theclinical situation suggested that any surgery for the fibroid at that moment was unnecessary and a decision for continuing the conservative management with vigilant monitoring for the size of the fibroid was taken.

The case illustrates that conservative management over surgery can sometimes be the right choice with good rewards. Also in developing countries, simple conservative measures have distinct advantages over surgery in terms of costs incurred for hospitalization, imaging procedures, blood transfusions and other medications.

\section{References}

1. Rock John A, Breech Lesley L. Leiomyomata Uteri and Myomectomy. In: Rock John A, Jones Howard W, Te Linde's Operative Gynecology, $10^{\text {th }}$ ed. South Asia Lippincott Williams \& Wilkins;2008.p.687,703

2. W.Laughlin SK, Baird DD, Savitz DA, Herring AH, Hartmann KE. Prevalence of uterine leiomyomas in the first trimester of pregnancy: an ultrasound-screening study. Obstet Gynecol 2009;113:630-5

3. Aharoni A, Reiter A, Golan D, Paltiely Y, Sharf M. Patterns of growth of uterine leiomyomas during pregnancy. $A$ prospective longitudinal study. $\mathrm{Br}$ ] Obstet Gynaecol 1988 ;95(5):510-3

4. Rosati P, Exacoustòs C, Mancuso S. Longitudinal evaluation of uterine myoma growth during pregnancy. A sonographic study. ] Ultrasound Med. 1992;11:511-5

5. Hee Joong Lee, Errol R Norwitz, Julia Shaw. Contemporary Management of Fibroids in Pregnancy. Rev Obstet Gynecol. 2010 Winter; 3(1): 20-7

6. Oruç S, Karaer O, Kurtul O. Coexistence of a prolapsed, pedunculated cervical myoma and pregnancy complications: a case report. J Reprod Med.2004 Jul;49(7):575-7

7. Celik C, Acar A, Ciçek N, Gezginc K, Akyürek C. Can myomectomy be performed during pregnancy? Gynecol Obstet Invest. 2002;53(2):79-83

8. Bonito M, Gulemì L, Basili R, Roselli D. Myomectomy during the first and second trimester of pregnancy. Clin Exp Obstet Gynecol. 2007;34(3):149-50

Cite this article as: Gandhi AC, Dugad HI, Shah Y. A rare presentation of cervical fibroid in pregnancy. Ann Afr Med 2014;13:88-90.

Source of Support: Nil. Conflict of Interest: None declared.

\section{Author Help: Online submission of the manuscripts}

Articles can be submitted online from http://www.journalonweb.com. For online submission, the articles should be prepared in two files (first page file and article file). Images should be submitted separately.

1) First Page File:

Prepare the title page, covering letter, acknowledgement etc. using a word processor program. All information related to your identity should be included here. Use text/rtt/doc/pdf files. Do not zip the files.

2) Article File:

The main text of the article, beginning with the Abstract to References (including tables) should be in this file. Do not include any information (such as acknowledgement, your names in page headers etc.) in this file. Use text/ $\mathrm{rtf} / \mathrm{doc} / \mathrm{pdf}$ files. Do not zip the files. Limit the file size to $1 \mathrm{MB}$. Do not incorporate images in the file. If file size is large, graphs can be submitted separately as images, without their being incorporated in the article file. This will reduce the size of the file.

3) Images:

Submit good quality color images. Each image should be less than $4096 \mathrm{~kb}(4 \mathrm{MB})$ in size. The size of the image can be reduced by decreasing the actual height and width of the images (keep up to about 6 inches and up to about $1800 \times 1200$ pixels). JPEG is the most suitable file format. The image quality should be good enough to judge the scientific value of the image. For the purpose of printing, always retain a good quality, high resolution image. This high resolution image should be sent to the editorial office at the time of sending a revised article.

4) Legends: Legends for the figures/images should be included at the end of the article file. 